\title{
An application of transintestinal intubation to the study of the colon ${ }^{1}$
}

\author{
A. TORSOLI, P. ARULlani, AND C. CASAlE \\ From the Institute of Medical Pathology, University of Rome, Italy
}

EDITORIAL COMmENT This technique has enabled biopsies to be taken from the right and left sides of the colon in 65 subjects. The same principle can be used for a variety of bowel studies.

Transintestinal intubation by means of a polyvinyl tube (Blankenhorn, Hirsch, and Ahrens, 1955) has been employed to collect samples of the gut contents at definite points (Blankenhorn and Ahrens, 1955; Levitan, Fordtran, Burrows, and Ingelfinger, 1962), to measure the length of the bowel and of its single segments (Hirsch, Ahrens, and Blankenhorn, 1956), and to record the intraluminal pressures (Fink and Friedmann, 1960). This tube appeared to be better tolerated than the conventional Miller-Abbot tube and the procedure could be prolonged for many days without any detectable disturbance (Blankenhorn et al., 1955).

We have found that transintestinal intubation provides useful guidance for the accurate positioning, at any point in the colon, of various instruments. By this method we have introduced first a Crosby biopsy capsule (Colagrande et al., 1964-66); secondly we have used the same procedure to position in the colon, by anterograde or retrograde routes, many other measuring or sampling devices. Recently, Provenzale, Camerada, and Revignas (1966) used transintestinal intubation to introduce a glass fibroscope into the caecum.

\section{DESCRIPTION OF THE TECHNIQUE}

The first phase is represented by conventional end-to-end intubation. A polyvinyl tube, $2 \mathrm{~mm}$. external and $1.5 \mathrm{~mm}$. internal diameter, is introduced nasally, the end is brought out in the mouth, joined to a rubber bag containing mercury, and then swallowed. The passage of the tube is followed by means of radio-television and in almost all normal cases is extruded from the anus after 48 to 120 hours. The rubber bag is recovered.

The second phase consists of the anterograde or retrograde introduction of instruments.

Anterograde introduction follows the joining of the oral head of the polyvinyl tube directly to the instruments,

${ }^{1}$ Aided by a grant from the C.N.R. (Consiglio Nazionale delle Ricerche) e.g., a radio pill or to a tube or tubes attached to the instrument itself (Crosby capsule, Shiner capsule, microballoons). After swallowing, slight tractions of the anal head of the tube (always under radio-television control) facilitates the progress of the instrument. The terminal ileum is reached about 10 to 60 minutes after swallowing. At this point, each traction of the anal head produces an immediate and proportional displacement of the instrument, which is easily conducted to the chosen point (Figs. 1 and 2). After measuring or collecting samples or

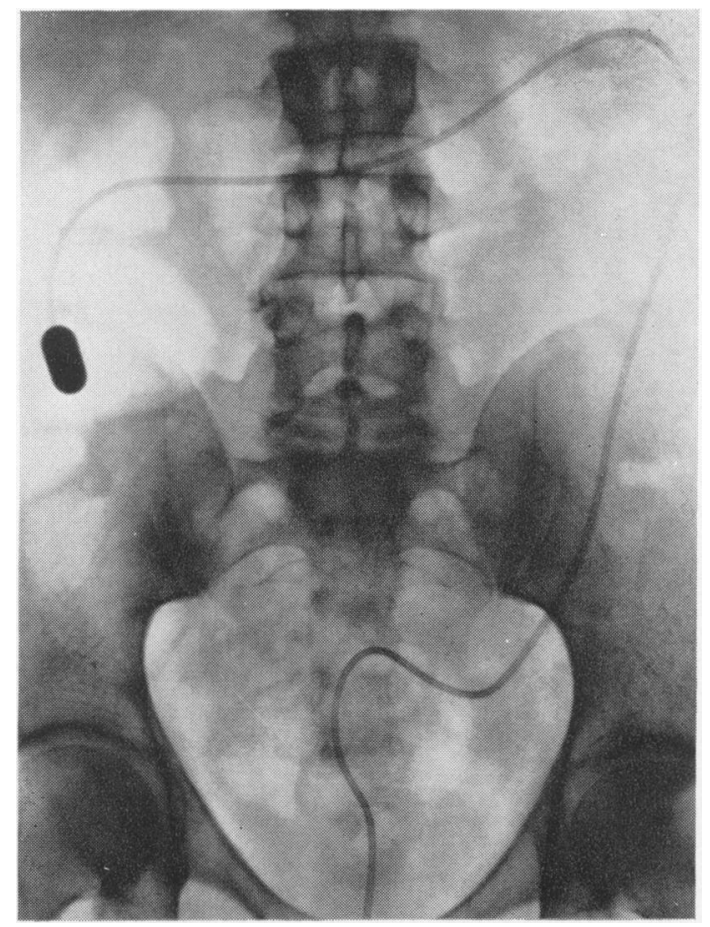

FIG. 1. A Crosby capsule in the ascending colon (anterograde introduction). 


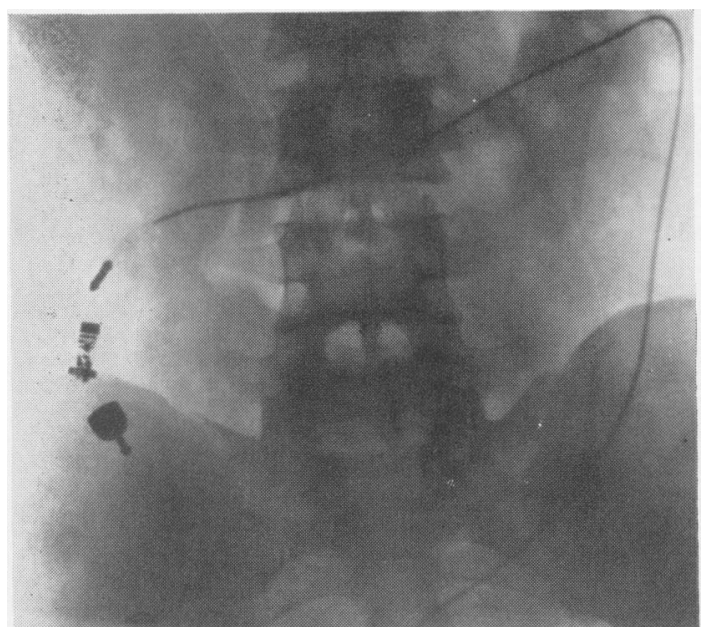

FIG. 2. A $\mathrm{pH}$ telemetering pill near the hepatic flexure (anterograde introduction).

biopsy specimens recovery of the instrument is immediate. In the same way, it is also possible to insert consecutively two or more instruments.

For retrograde introduction it is necessary to pull through the anal head of the polyvinyl tube, so that colonic curves may be reduced. In this way a glass fibroscope can be pushed upwards following the polyvinyl tube (Figs. 3 and 4). The head of the fibroscope provides a central channel through which may be run a length of plastic tube.

According to Provenzale et al. (1966), retrograde introduction of instruments can be performed by means of a bend before the ileo-caecal valve, through which runs a double tube with the ends projecting out of the anus. Traction of one end causes the other one to ascend.

Gastrointestinal intubation is controlled by radiotelevision, on an average of five times per patient. The single controls did not exceed $20 \mathrm{sec}$. $(0 \cdot 15 \mathrm{~mA} / \mathrm{sec}$. 90KV).

During biopsy or telemetering records or aspiration of intestinal contents, the radio-television controls, performed with the same values, did not exceed three minutes. Therefore the irradiation for each patient did not exceed $50 \mathrm{~mA} / \mathrm{sec}$. One abdominal plain radiograph $(90 \mathrm{KV} ; 300 \mathrm{~mA} / \mathrm{sec} .0 .2 \mathrm{sec}$.) has an irradiation value equal to $60 \mathrm{~mA} / \mathrm{sec}$.

\section{DISCUSSION}

Transintestinal pilot intubation permits the introduction of instruments to any position in the colon. By means of anterograde introduction we have been able to perform biopsies of the right and left colon in more than 65 subjects as well as various experiments on intraluminal pressure, measurements of $p H$, and collection of samples. The biopsy specimens are available for electron microscopy. Preliminary

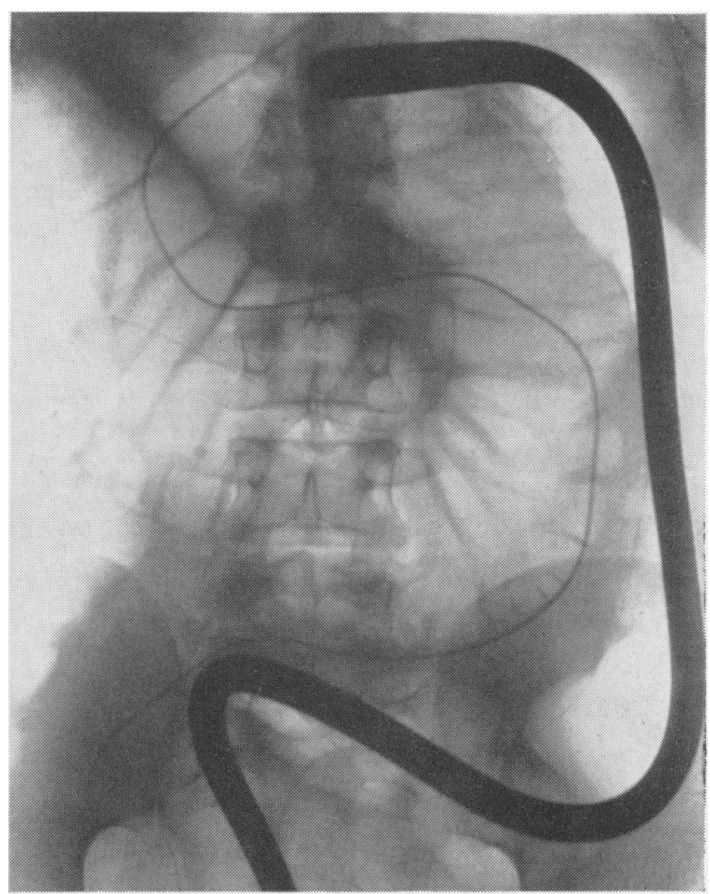

FIG. 3. A glass fibroscope at the splenic flexure (retrograde introduction).

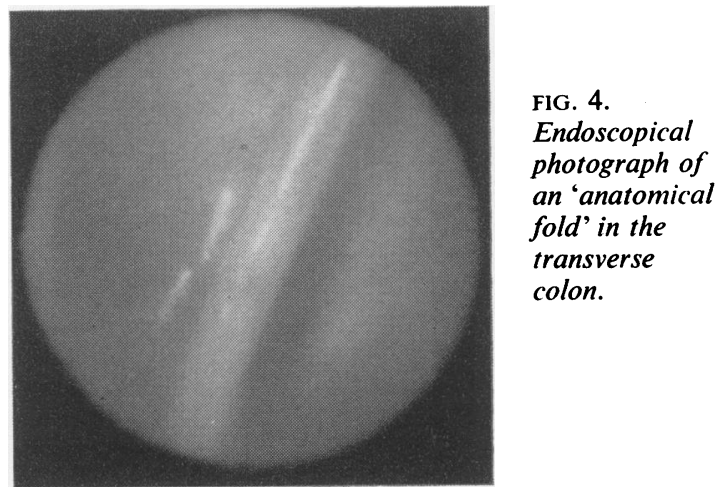

results of the histological studies are being published elsewhere (Fabbrini, Torsoli, Alessandrini, Onori, Greco, Arullani, and Casale, 1966; Cassano, et al., 1966).

Anterograde introduction of instruments is not uncomfortable and does not cause alterations in the gut or bleeding. From a physiological point of view, this route is preferable to retrograde introduction. The latter may provoke some minor discomfort.

Transintestinal intubation is of course contraindicated when a tract of intestine is narrowed. 


\section{SUMMARY}

Transintestinal intubation provides a useful technique to guide the physician in positioning, at any point in the colon, various measuring, sampling, or observing devices. The general principles of this procedure are described in this paper.

\section{REFERENCES}

Blankenhorn, D. H., and Ahrens, E. H., Jr. (1955). Extraction, isolation, and identification of hydrolitic products of triglyceride digestion in man. J. biol. Chem., 212, 69-81.

_-, Hirsch, J., and Ahrens, E. H., Jr. (1955). Transintestinal intubation: technic for measurement of gut length and physiologic sampling at known loci. Proc. Soc. exp. Biol. (N.Y.), 88, 356-362.
Cassano, C., and Torsoli, A. (1966). Indirizzi moderni nello studio delle malattie croniche non neoplastiche del colon. Relaz. 67th Congr. Soc. It. Med. Int.

Colagrande, C., and Arullani, P. (1964). La biopsia del colon. Arch. ital. Mal. Appar. dig., 31, 369-374.

Colagrande, C., Arullani, P., and Casale, C. (1966). A suction-biopsy procedure for obtaining specimens of mucosa from the right and left colon. Amer. J. dig. Dis., 11, 389-393.

Fabbrini, A., Torsoli, A., Alessandrini, A., Onori, L., Greco, V., Casale, C., Arullani, P., and Re, M. (1966). Surface microscopy of the large bowel. Experientia, 22, 408-410.

Fink, S., and Friedman, G. (1960). The differential effect of drugs on the proximal and distal colon. Amer. J. Med., 28, 534-540.

Hirsh, J., Ahrens, E. H., Jr., and Blankenhorn, D. H. (1956). Measurement of the human intestinal length in vivo and some causes of variation. Gastroenterology, 31, 274-284.

Levitan, R., Fordtran, J. S., Burrows, B. A., and Ingelfinger, F. J. (1962). Water and salt absorption in the human colon. $J$. clin. Invest., 41, 1754-1759.

Provenzale, L., Camerada, P., and Revignas, A. (1966). La coloscopia totale trans-anale mediante una metodica originale. Rass. med. sarda., 69, 149-160. 